\title{
Efeito de promotores de crescimento alternativos no desempenho e no custo de produção de frangos de corte
}

\author{
Patrícia Tomazini Medeiros ${ }^{1 *}$ \\ Marília Terezinha Sangoi Padilha \\ José Carlos Fiad Padilha ${ }^{2}$ \\ Filipe Espíndola ${ }^{1}$ \\ Rogério Maggioni ${ }^{1}$ \\ ${ }^{1}$ Macedo Agroindustrial Ltda, Departamento de Nutrição Animal \\ CEP 88104-800, São José - SC, Brasil \\ ${ }^{2}$ Departamento de Zootecnia e Desenvolvimento Rural \\ Universidade Federal de Santa Catarina, Florianópolis - SC, Brasil \\ *Autor para correspondência \\ patriciatomazini@hotmail.com
}

Submetido em 22/08/2008

Aceito para publicação em 13/03/2009

\section{Resumo}

Com o objetivo de avaliar o desempenho e o custo de produção de frangos de corte, foram testados probióticos e prebióticos como promotores de crescimento alternativos aos antimicrobianos (colistina/ avilamicina), na ração de 6.450 pintos de corte, machos, da linhagem Cobb, criados de 1 a 42 dias de idade, distribuídos em um delineamento inteiramente casualisado, formado por oito tratamentos de rações experimentais, com 13 - 17 repetições de 50 aves cada por tratamento. Os probióticos foram o Bacillus subtilis em diferentes concentrações e/ou recomendação de uso, uma mistura de Saccharomyces cerevisiae mais Aspergillus oryzae ou um prebiótico composto de mananoligossacarídeos (MOS) adicionados em uma ração inicial e outra de crescimento comum a todos os tratamentos. Não se verificou diferenças significativas na conversão alimentar entre tratamentos. Entretanto, o peso médio dos animais que receberam Bacillus subtilis $\left(1,6 \times 10^{9} \mathrm{CFU} / \mathrm{g}\right)$ ou uma mistura de probióticos foi maior ou semelhante ao peso das aves alimentadas com os antimicrobianos. Conclui-se que é possível substituir os antimicrobianos utilizados, pelos probióticos avaliados como promotores de crescimento sem prejuízos no desempenho e no custo de produção de frangos de corte.

Unitermos: frangos de corte, antimicrobianos, probióticos, prebióticos, desempenho

\section{Abstract}

Effects of alternative promoters of growth on the performance and cost of production of broilers. Probiotics and prebiotics were compared to antimicrobials as alternative growth promoters in male broilers grown from 1 to 42 days of age. Eight treatments were evaluated: a control feed without antimicrobials or alternative growth promoters, a control feed with antimicrobials, a control feed with the antimicrobials colistine and avilamicine, three rations with probiotic Bacillus subtilis in different concentrations and/or under recommended usage, one ration with probiotic Saccharomyces cerevisiae in addition to a mixture of probiotic 
Bacillus subtilis, Saccharomyces cerevisiae and Aspergillus oryzae, and one ration with mananoligossacarids (MOS) plus betaglutanes. Antimicrobials and alternative growth promoters were added to an initial feed and to a growth feed common to all birds. Thirteen to 17 replicates of 50 birds of a Cobb line were utilized per treatment in a completely randomized design. Feed consumption, feed conversion and production costs did not significantly differ among treatments. The weights of 42-day-old birds fed on Bacillus subtilis $\left(1,6 \times 10^{9} \mathrm{CFU} / \mathrm{g}\right)$ or the mixture of probiotics were higher or similar to the weights of birds fed on ration with antimicrobials. It was concluded that probiotics can replace antimicrobials as growth promoters for broilers up to 42 days of age without negative effects on growth performance and production cost.

Key words: broilers, antimicrobial, probiotics, prebiotics, performance

\section{Introdução}

No início da avicultura industrial, por volta de 1950, a utilização de antimicrobianos (antibióticos e quimioterápicos) tinha o intuito de prevenir enfermidades, com o passar do tempo, começaram a ser usados também como promotores de crescimento. Nos Estados Unidos os antimicrobianos têm sido usados como promotores de crescimento na produção animal há 50 anos (Dibner e Richards, 2005). Os antimicrobianos são produzidos por microorganismos visando garantir sua proteção, desenvolvimento e perpetuação da espécie. O homem usa a capacidade que alguns microorganismos têm de produzir antibiótico, com fins terapêuticos (Palermo, 2006).

Os promotores de crescimento tem sido geralmente antimicrobianos utilizados em doses baixas nas rações. A constante exposição dos animais a estes produtos pode levar a seleção de uma biota resistente. A partir da década de 80 , pesquisadores começaram a notar que determinadas cepas bacterianas haviam se tornado resistentes aos antibióticos utilizados em aves e que o uso continuado de antimicrobianos promotores de crescimento, servia para expandir um "pool" de genes de resistência na natureza, sendo recomendada a rotação de produtos. A grande preocupação é que bactérias resistentes em animais de produção possam contribuir para a resistência aos antibióticos em humanos (Sader, 2004). A resistência se desenvolve quando uma bactéria sobrevive a exposição de um antibiótico que normalmente mata a população bacteriana. Normalmente ocorre uma mutação que permite a sobrevivência da bactéria exposta ao antibiótico (Edens, 2003). A resistência antimicrobiana é um problema com graves implicações clínicas, pois novos agentes antimicrobianos devem ser desenvolvidos e são sempre mais caros e muitas vezes mais tóxicos que os utilizados anteriormente nos tratamentos das infecções.

Portanto, um dos maiores desafios na área de produção animal tem sido à busca de alternativas para se reduzir o uso de antimicrobianos como promotores de crescimento em rações. Este desafio é consequência das crescentes pressões impostas por legislações de países que importam produtos de origem animal, como os da Comunidade Européia, um dos maiores importadores de carne de frango, que proíbem a inclusão de antimicrobianos nas dietas de frangos de corte e outras espécies animais. Entretanto, autores como Langhout (2005) alegam que a retirada gradativa dos antibióticos promotores de crescimento de dietas de frangos, reduzirá o desempenho técnico e a lucratividade do setor avícola. Estas restrições por parte dos importadores e os impactos destas alterações no custo de produção, tem levado os nutricionistas a pesquisar alternativas que auxiliem na melhora do desempenho dos animais, mas que sejam inócuos para o animal e para o homem (Dibner e Richards, 2005).

Neste contexto, as pesquisas passaram a ter um novo enfoque visando desenvolver alternativas, onde os seus mecanismos de ação teriam que ser no sentido da não eliminação de biotas e o consequente aparecimento de resistência, mas sim na ação competitiva, isto é favorecer a multiplicação de microorganismos que produzam substâncias antimicrobianas capazes de aderirse à mucosa intestinal e impedir a fixação de bactérias enteropatogênicas (Ahmad, 2006).

Segundo Flemming e Freitas (2005), os transtornos entéricos dos animais associados à proibição do uso de promotores de crescimento levaram os pesquisadores a desenvolver alternativas, e dentre elas uma das mais 
viáveis é a cultura de microorganismos desejáveis, que povoem o tubo digestivo, associada a fatores que favoreçam a multiplicação desses, proporcionando uma condição de equilíbrio. Os microorganismos capazes de se multiplicar e adaptar-se rapidamente ao meio intestinal da maioria dos animais e ainda deprimir a proliferação daqueles considerados indesejáveis, são os pertencentes ao grupo dos probióticos e os agentes favorecedores à instalação dos probióticos no meio intestinal são os prebióticos. Nos últimos anos, o uso de probióticos na profilaxia e terapia de enfermidades gastrointestinais tem sido objeto de grande interesse e de controvérsia científica. Hoje em dia se reconhece a importância e a possível eficácia da terapia biótica (probióticos e prebióticos) como ferramenta médica para o tratamento de enfermidades digestivas (Nava e Davila, 2004). Os probióticos, compostos a base de microorganismos vivos isolados da própria biota dos animais e os prebióticos isolados, geralmente, a partir de oligossacarídeos, têm sido indicados como alternativas que auxiliam na proliferação destas biotas e no equilíbrio do meio intestinal do hospedeiro, favorecendo o seu desempenho produtivo.

Segundo Santos e Turnes (2005), os probióticos vêm sendo utilizados há anos na alimentação humana, tanto com finalidade profilática como terapêutica. Embora existam vários estudos que mostram seus benefícios como aditivos na alimentação animal, ainda há certa resistência por parte do setor industrial avícola em sua utilização. Diversos trabalhos têm sido publicados sobre o uso de bactérias probióticas (Lactobacillus, Bifidobacterium, Enterococcus e Bacillus subtilis) na produção de diferentes espécies de animais zootécnicos, assim como é crescente a gama de produtos que têm sido disponibilizados para este fim no mercado. Na produção de aves, alguns têm apresentado resultados positivos e outros negativos levando ou não em consideração seus impactos no custo de produção.

O objetivo deste trabalho foi estudar o efeito de promotores de crescimento alternativos aos antimicrobianos no desempenho dos animais e o custo de um quilo de frango vivo produzido.

\section{Material e Métodos}

O experimento foi conduzido no município de Palhoça-SC, na granja experimental da empresa Macedo Agroindustrial Ltda, entre setembro e novembro de 2006. O galpão utilizado para o experimento possui 100 metros de comprimento por $12 \mathrm{~m}$ de largura, subdividido em 174 boxes de $5 \mathrm{~m}^{2}$, com capacidade de alojamento de 50 aves cada. Todos os boxes receberam uma camada de cepilho (maravalha de madeira), de aproximadamente $20 \mathrm{~cm}$ de altura e uma ficha de identificação na qual foi registrado, além do número do box e do tratamento, os dados de mortalidade, consumo de ração e de peso vivo das aves, durante o período experimental.

A temperatura e a umidade dentro do galpão foram registradas com o auxílio de termo-higrômetro e foram utilizadas campânulas e cortinas plásticas, para manter a temperatura adequada às necessidades das aves, durante o período experimental.

Foram utilizados 6.450 pintos de um dia, machos de corte da linhagem Cobb, alojados nos boxes experimentais de $5 \mathrm{~m}^{2}$, criados de 1 a 42 dias de idade. As aves foram distribuídas num delineamento inteiramente ao acaso, formado por oito tratamentos com $13-17$ repetições de 50 aves. Os dados obtidos foram avaliados pela análise de variância e as médias comparadas pelo teste de Tukey ao nível de 5\%. Cada tratamento correspondeu a um tipo de ração base, comum a todos, onde foi incorporado um aditivo específico com função de promotor de crescimento.

Os tratamentos foram constituídos por:

- Tratamento A - Controle Positivo (dieta basal, 20ppm de colistina / 10ppm de avilamicina);

- Tratamento B - Controle Negativo (dieta basal, sem aditivo);

- Tratamento C - Controle Negativo + Bacillus subtilis $\left(10^{10} \mathrm{CFU} / \mathrm{g}\right.$ de alimento);

- Tratamento D - Controle Negativo + Bacillus subtilis $\left(10^{9} \mathrm{CFU} / \mathrm{g}\right.$ de alimento);

- Tratamento E - Controle Negativo + Bacillus subtilis $\left(1,6 \times 10^{9} \mathrm{CFU} / \mathrm{g}\right)$;

- Tratamento F - Controle Negativo + uma mistura de Bacillus subtilis ( $3 \times 10^{11} \mathrm{CFU} / \mathrm{g}$ ), Sac- 
charomyces cerevisiae $\left(2 \times 10^{11} \mathrm{CFU} / \mathrm{kg}\right)$ e $A s$ pergillus oryzae $\left(4 \times 10^{9} \mathrm{CFU} / \mathrm{kg}\right)$;

- Tratamento G - Controle Negativo + Mananoligossacarídeos e Betaglucanos;

- Tratamento H - Controle Negativo + Saccharomyces cerevisiae.

Na Tabela 1, estão descritos os tratamentos, tipos, concentrações e dosagem dos aditivos.

TABELA 1: Descrição dos tratamentos, tipos, concentrações e dosagem dos aditivos.

\begin{tabular}{|c|c|c|c|}
\hline Tratamento & Tipo de aditivo & $\begin{array}{c}\text { Concentração } \\
\text { do produto }\end{array}$ & $\begin{array}{c}\text { Dosagem } \\
(\mathrm{kg} / \mathrm{t})\end{array}$ \\
\hline A & Controle & $\begin{array}{c}20 \mathrm{ppm} \\
\text { colistina/ } \\
10 \mathrm{ppm} \\
\text { avilamicina }\end{array}$ & $\begin{array}{c}0,20 \mathrm{e} \\
0,15\end{array}$ \\
\hline B & Controle negativo & \begin{tabular}{|c|} 
sem \\
antimicrobianos \\
ou alternativos
\end{tabular} & - \\
\hline $\mathrm{C}$ & Bacilus subtilis & $10^{10} \mathrm{CFUs} / \mathrm{g}$ & 0,03 \\
\hline $\mathrm{D}$ & Bacilus subtilis & $10^{9} \mathrm{CFUs} / \mathrm{g}$ & 0,15 \\
\hline $\mathrm{E}$ & $\begin{array}{l}\text { Bacilus subtilis } \\
\text { Bacilus subtilis }\end{array}$ & $\begin{array}{l}1,6 \times 10^{9} \mathrm{CFUs} / \mathrm{g} \\
3 \times 10^{11} \mathrm{CFUs} / \mathrm{g} \\
\end{array}$ & 0,50 \\
\hline $\mathrm{F}$ & $\begin{array}{c}\text { Saccharomyces } \\
\text { cerevisiae } \\
\text { Aspergillus oryzae }\end{array}$ & \begin{tabular}{|l|}
$2 \times 10^{11} \mathrm{CFUs} / \mathrm{g}$ \\
$4 \times 10^{9} \mathrm{CFUs} / \mathrm{g}$ \\
\end{tabular} & 0,50 \\
\hline G & $\begin{array}{c}\text { Mananoligossacarídeos } \\
+ \text { Betaglucanos }\end{array}$ & - & 1 \\
\hline $\mathrm{H}$ & $\begin{array}{c}\text { Saccharomyces } \\
\text { cerevisiae }\end{array}$ & - & 2 \\
\hline
\end{tabular}

*CFUs: Unidades formadoras de colônias.

A ração inicial (1-21 dias) e a ração de crescimento (22-42 dias) foram formuladas de acordo com as recomendações nutricionais das Tabelas Brasileiras para Aves e Suínos (Rostagno et al., 2005) com 3.100kcal e $3.150 \mathrm{kcal}$ de energia metabolizável $/ \mathrm{kg}$, respectivamente. Os preços das rações referem-se a valores praticados em 2006. Na Tabela 2, estão especificadas as composições percentuais das rações e, na Tabela 3, a composição química das mesmas.
TABELA 2: Composição percentual na matéria natural das rações experimentais usadas como base para todos os tratamentos para as fases iniciais e crescimento.

\begin{tabular}{l|c|c}
\hline \multicolumn{1}{c|}{ Ingredientes (\%) } & $\begin{array}{c}\text { Inicial } \\
(1-21 \text { dias })\end{array}$ & $\begin{array}{r}\text { Crescimento } \\
(22-42 \text { dias })\end{array}$ \\
\hline Milho & 25,06 & 5,00 \\
Sorgo & 35,00 & 55,00 \\
Farinha de carne & 5,81 & 5,54 \\
Farelo de soja & 28,09 & 28,26 \\
Farinha de ostras & 0,99 & 0,77 \\
Óleo de frango & 3,78 & 4,41 \\
Sal & 0,37 & 0,33 \\
Cloreto de colina & 0,04 & 0,00 \\
Metionina & 0,35 & 0,35 \\
Lisina & 0,21 & 0,04 \\
Premix Vitamínico Inicial & \\
Premix Vitamínico Crescimento $^{3}$ & 0,20 & - \\
Premix Mineral $^{4}$ & - & 0,20 \\
Aditivo promotor de crescimento $^{5}$ & 0,10 & 0,10 \\
TOTAL & $(-)$ & $(-)$ \\
\hline
\end{tabular}

${ }^{1}$ Produto comercial com $60 \%$ de Cloreto de colina. ${ }^{2}$ Composição mínima em UI ou em mg do premix vitamínico inicial por $1.000 \mathrm{~kg}$ de ração: Vit. A, 10.000.000; Vit. D3, 2.500.000; Vit. E, 50.000; Vit. K, 2.300; Vit. B1, 2.000; Vit. B2, 6.000; Vit. B6, 3.360; Vit. B12, 15; Ácido fólico, 980; Ácido nicotínico, 34.000; Pantotenato de cálcio, 12.000; Biotina, 100; Coccidiostático, 6ppm. ${ }^{3}$ Composição mínima em UI ou em mg do premix vitamínico crescimento por $1.000 \mathrm{~kg}$ de ração: Vit. A, 8.230.000; Vit. D3, 1.900.000; Vit. E, 50.000; Vit. K, 2.000; Vit. B1, 1.500; Vit. B2, 4.800; Vit. B6, 2.880; Vit. B12, 12; Ácido fólico, 750; Ácido nicotínico, 30.000; Pantotenato de cálcio, 10.000; Biotina, 80; Coccidiostático, 65 ppm. ${ }^{4}$ Composição mínima em UI ou em mg do premix mineral por $1.000 \mathrm{~kg}$ de ração: Ferro, 48.400; Cobre, 12.500; Manganês inorgânico, 120.000; Zinco inorgânico, 100.000; Iodo, 930; Selênio, 300. ${ }^{5}$ Aditivo específico para cada tratamento conforme Tabela (1).

Durante o experimento, foi registrado o Peso Final (PF), a Ração Consumida (RC) e a Mortalidade $(\mathrm{M}=\%$ animais mortos/box). Foram calculados os parâmetros zootécnicos: Peso Médio $\left(\mathrm{PM}=\mathrm{PF} / \mathrm{N}^{\circ} \mathrm{de}\right.$ animais), o Ganho de Peso Diário (GPD = PM/idade) e a Conversão Alimentar $(\mathrm{CA}=\mathrm{RC} / \mathrm{PF})$. Considerando todo o período experimental foi calculado o custo de um quilo de frango vivo produzido, o Fator de Produção

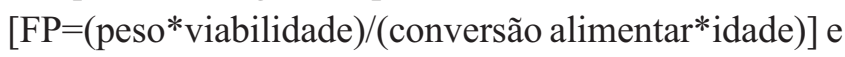
o Índice de Eficiência Produtiva [IEP=(peso final*100)/ conversão alimentar)]. 
TABELA 3: Composição química das rações experimentais, na matéria natural, adaptados das Tabelas Brasileiras para Aves e Suínos (Rostagno et al., 2005).

\begin{tabular}{l|c|c}
\hline $\begin{array}{c}\text { Composição química } \\
\text { calculada (\%) }\end{array}$ & $\begin{array}{c}\text { Inicial } \\
(1-21 \text { dias })\end{array}$ & $\begin{array}{c}\text { Crescimento } \\
\text { (22-42 dias) }\end{array}$ \\
\hline Matéria Seca & 84,12 & 83,90 \\
EM (kcal/kg) & 3.100 & 3.150 \\
Proténa Bruta & 20,49 & 20,50 \\
Gordura & 6,89 & 7,29 \\
Fibra & 3,26 & 3,27 \\
Metionina+Cistina & 0,87 & 0,88 \\
Lisina & 1,18 & 1,09 \\
Cálcio & 1,00 & 0,95 \\
Fósforo & 0,44 & 0,62 \\
Sódio & 0,20 & 0,18 \\
Cloro & 0,32 & 0,28 \\
Potássio & 0,78 & 0,78 \\
\hline
\end{tabular}

\section{Resultados e Discussão}

Durante o período experimental a média das temperaturas registradas foi de $20,27^{\circ} \mathrm{C}$, onde as mínimas e máximas absolutas foram de 11,30 e $32,00^{\circ} \mathrm{C}$, respectivamente. A umidade relativa do ar foi de $69 \%$, oscilando entre 39 e $96 \%$. Os valores registrados são considerados normais para o período e região onde foi realizado o experimento.

A utilização ou não de antimicrobianos como promotores de crescimento não interferiu no consumo de ração, conversão alimentar e no percentual de mortalidade dos frangos de corte entre $0-42$ dias de idade $(\mathrm{P}<0,05)$.

Cada tratamento correspondeu a um tipo de ração base comum a todos onde foi incorporado um aditivo específico, com função de promotor de crescimento. Foi observado que não houve diferença estatisticamente significativa entre os tratamentos nos itens consumo de ração, mortalidade, conversão alimentar e custo do $\mathrm{kg}$ de frango vivo. Porém os tratamentos E e F conseguiram manter o peso vivo e consequentemente o ganho de peso diário estatisticamente igual ao tratamento A (controle positivo). Os resultados zootécnicos e econômicos estão apresentados na Tabela (4).

Desconsiderando as variáveis que não obtiveram diferenças estatisticamente significativas o tratamento E foi o que obteve o melhor custo/beneficio (Tabela 4), isso considerando os riscos do tratamento $\mathrm{B}$ num sistema de produção em maior escala.

TABELA 4: Resultados de Peso Médio (PM), Ganho de Peso Diário (GPD), Ração Consumida (RC), Conversão Alimentar (CA), Mortalidade (MORT), Fator de Produção (FP), Índice de Eficiência Produtiva (IEP) e Custo do $\mathrm{kg}$ de frango vivo (CUSTO/kg) em frangos de corte, no período de 0 a 42 dias de idade.

\begin{tabular}{|c|c|c|c|c|c|c|c|c|c|c|}
\hline \multicolumn{2}{|c|}{ TRAT N* } & PM & \multicolumn{2}{|l|}{ GPD } & $\mathrm{RC}$ & $\mathrm{CA}$ & MORT & FP & IEP & CUSTO $/ \mathrm{kg}$ \\
\hline $\mathbf{A}$ & 17 & 3,058 a & $65,1 \mathrm{a}$ & & 5,364 a & 1,754 a & $5,41 \%$ a & 351,1 a & 174,4 a & R\$ 0,976 a \\
\hline B & 17 & 2,966 & 63,1 & & 5,271 a & 1,776 a & $4,71 \%$ a & 338,8 a & $167,0 \mathrm{a}$ & $\mathrm{R} \$ 0,962 \mathrm{a}$ \\
\hline $\mathrm{C}$ & 17 & $2,992 \quad b \quad c$ & $63,7 \quad b$ & & $5,254 \mathrm{a}$ & $1,756 \mathrm{a}$ & $2,00 \% \mathrm{a}$ & 355,6 a & 170,6 a & $\mathrm{R} \$ 0,953 \mathrm{a}$ \\
\hline $\mathrm{D}$ & 17 & $2,976 \quad b \quad c$ & $63,3 \quad b$ & & 5,226 a & $1,756 \mathrm{a}$ & $5,18 \%$ a & 342,4 a & 169,6 a & $\mathrm{R} \$ 0,959 \mathrm{a}$ \\
\hline $\mathbf{E}$ & 16 & 3,035 a b & 64,4 a b & & 5,363 a & 1,773 a & $3,88 \%$ a & 349,2 a & 170,8 a & R\$ 0,963 a \\
\hline $\mathrm{F}$ & 16 & $3,007 \mathrm{a} b$ & $64,0 \mathrm{a} \mathrm{b}$ & & 5,292 a & $1,760 \mathrm{a}$ & $5,25 \%$ a & 344,3 a & $170,8 \mathrm{a}$ & $\mathrm{R} \$ 0,966 \mathrm{a}$ \\
\hline G & 13 & 2,969 & 63,2 & C & 5,193 a & 1,749 a & $3,69 \%$ a & 348,6 a & $170,0 \mathrm{a}$ & $\mathrm{R} \$ 0,959 \mathrm{a}$ \\
\hline $\mathrm{H}$ & 16 & $2,975 \quad b \quad c$ & $63,3 \quad b$ & $\mathrm{c}$ & $5,239 \mathrm{a}$ & $1,761 \mathrm{a}$ & $2,88 \%$ a & 349,6 a & $169,2 \mathrm{a}$ & $\mathrm{R} \$ 0,965 \mathrm{a}$ \\
\hline
\end{tabular}

Números seguidos de letras iguais na vertical são estatisticamente iguais. *Número de repetições de 50 aves cada. Tratamento A - Controle Positivo (dieta basal, 20ppm de colistina/10ppm de avilamicina); Tratamento B - Controle Negativo (dieta basal, sem aditivo); Tratamento $\mathrm{C}-$ Controle Negativo + Bacillus subtilis $\left(10^{10} \mathrm{CFU} / \mathrm{g}\right.$ de alimento); Tratamento D - Controle Negativo + Bacillus subtilis $\left(10^{9} \mathrm{CFU} / \mathrm{g}\right.$ de alimento); Tratamento E - Controle Negativo + Bacillus subtilis $\left(1,6 \times 10^{9} \mathrm{CFU} / \mathrm{g}\right)$; Tratamento F - Controle Negativo + uma mistura de Bacillus subtilis $\left(3 \times 10^{11} \mathrm{CFU} / \mathrm{g}\right)$, Saccharomyces cerevisiae $\left(2 \times 10^{11} \mathrm{CFU} / \mathrm{kg}\right)$ e Aspergillus oryzae $\left(4 \times 10^{9} \mathrm{CFU} / \mathrm{kg}\right)$; Tratamento G - Controle Negativo + Mananoligossacarídeos e Betaglucanos e Tratamento H - Controle Negativo + Saccharomyces cerevisiae. 
Embora não tenha sido detectada diferenças estatisticamente significativas em relação ao tratamento testemunho positivo, o tratamento $\mathrm{C}$ apresentou resultados zootécnicos próximos do satisfatório (Tabela 4) e deve-se num próximo experimento testar outras concentrações do produto.

O desempenho geral dos frangos de corte neste experimento comparando os que receberam ou não antimicrobianos ou os compostos alternativos foi semelhante aos detectados por Ojeda et al. (2007), que não observaram diferença nos índices produtivos dos animais que receberam os antimicrobianos avilamicina ou os que receberam os probióticos (Poultry5star e mescla fitobiótica PEP) na ração. No trabalho de Pelícia et al. (2004), podemos constatar que a substituição de promotores químicos por biológicos não afetou o desempenho, carcaças e rendimentos de cortes, e as características da qualidade de carne.

Foi observado, no trabalho de Maiorka et al. (2001), que a utilização de simbióticos (prebióticos + probióticos) na dieta de frangos de corte é uma alternativa viável na avicultura de corte, pois não foram observadas diferenças significativas no desempenho das aves quando comparadas ao grupo tratado com antibióticos. Outros resultados benéficos com o uso de probióticos tem sido reportados por diferentes autores como Corrêa et al. (2003), Lima et al. (2003) e Takahashi et al. (2005). Entretanto, no trabalho realizado por Loddi et al. (2000) aves suplementadas também com promotores biológicos, só que neste caso foi utilizado o probiótico Enterococcus faecium Cernelle 68 em substituição ao promotor de crescimento químico (avoparcina) apresentaram menor desempenho geral $(\mathrm{P}<0,05)$ com redução no peso final, ganho de peso e consumo de ração, mas a conversão alimentar não diferiu em nenhuma das fases da criação. No trabalho de Pelicano et al. (2004), utilizando alternativas aos promotores de crescimento como o probiótico Bacillus subtilis ou prebióticos como o MOS, os autores também não observaram efeito benéfico no desempenho das aves.

A comparação de resultados de estudos científicos conduzidos com aditivos deve ser sempre relativizada, uma vez que em cada experimento são utilizados determinados tipos de promotores de crescimento, com diferentes dosagens e formas de administração e em condições experimentais distintas (Boratto et al., 2004).

Foi concluído que os aditivos alternativos aos antimicrobianos não alteraram a conversão alimentar dos frangos de corte em relação aos que receberam ração com antimicrobianos. Quando estes resultados são associados ao peso vivo, ganho de peso e ao custo de produção de um quilo de peso vivo eles indicam a viabilidade de substituição dos antimicrobianos, por probióticos ou uma mistura de probióticos como promotores de crescimento.

\section{Referências}

Ahmad, I. 2006. Effect of probiotics on broilers performance. International Journal of Poultry Science, 5 (6): 593-597.

Boratto, A. J.; Lopes, D. C.; Oliveira, R. F. M.; Albino, L. F. T.; Sá, L. M.; Oliveira, G. A. 2004. Uso antibióticos, de probióticos e de homeopatia, em frangos de corte criados em ambiente de conforto, inoculados ou não com Escherichia coli. Revista Brasileira de Zootecnia, 33 (6): 1477-1485.

Corrêa, G. S. S.; Gomes, A. V. C.; Corrêa, A. B.; Salles, A. S., Mattos, E. S. 2003. Efeito de antibiótico e probiótico sobre o desempenho e rendimento de carcaça de frangos de corte. Arquivo Brasileiro de Medicina Veterinária e Zootecnia, 55 (4): 467-473.

Dibner, J. J.; Richards, J. D. 2005 Antibiotic growth promoters in agriculture: History and mode of action. Poultry Science, 84: 634.

Edens, F. W. 2003. A alternative for antibiotic use in poultry: Probiotics. Revista Brasileira de Ciência Avícola, 5 (2): 75-97.

Flemming, J. S; Freitas, R. J. S. 2005. Avaliação do efeito de prebióticos (MOS), probióticos (Bacillus licheniformis e Bacillus subtillis) e promotores de crescimento na alimentação de frangos de corte. Archives of Veterinary Science, 10 (2): 41-47.

Langhout, P. 2005. Alternativas ao uso de quimioterápicos na dieta de aves: A visão da indústria e recentes avanços. Anais Fundação Apinco de Ciência e Tecnologia Avícolas, Campinas, Brasil, p.2133.

Lima, A. C. F.; Júnior, J. M. P.; Macari, M.; Malheiros, E. B. 2003. Efeito do uso de probiótico sobre o desempenho e atividade de enzimas digestivas de frangos de corte. Revista Brasileira de Zootecnia, 32 (1): 200-207.

Loddi, M. M.; Gonzales, E.; Takita, T. S.; Mendes, A. A.; Roça, R. O. 2000. Uso de probiótico e antibiótico sobre o desempenho, rendimento e a qualidade de carcaça de frangos de corte. Revista Brasileira de Zootecnia, 29 (4): 1124-1131.

Maiorka, A.; Santin, E.; Sugeta, S. M.; Almeida, J. G.; Macari, M. 2001. Utilização de prebióticos, probióticos ou simbióticos em dietas para frangos. Revista Brasileira de Ciência Avícola, 3 (1): 75-82.

Nava, G. M.; Davila, V. 2004. Nuevas perspectivas en la selección y evaluación de probióticos. Revista Chilena de Nutrición, 31, suppl., 1: 184-185. 
Ojeda, A. A.; Aragón, Y. A.; Sanchez, B. R.; Lon-Wo, E.; Pasteiner, S.; Mohnl, M. 2007. Efecto de los promotores de crecimiento naturales en el comportamiento productivo, rendimiento cárnico y salud intestinal de los pollos de ceba. Anais do XX Congresso Latinoamericano de Avicultura, Porto Alegre, Brasil, p.7-9.

Palermo, J. N. 2006. Uso de medicamentos veterinários: Impactos na moderna avicultura. Anais do Simpósio Brasil Sul de Avicultura, Chapecó, Brasil, p.70-78.

Pelicano, E. R. L; Souza, P. A.; Souza, H. B. A; Oba, A.; Norkus, E. A; Kodawara, L. M.; Lima, T. M. A. 2004. Performance of broilers fed diets containing natural growth promoters. Revista Brasileira de Ciência Avícola, 6 (4): 231-236.

Pelícia, K.; Mendes A. A.; Saldanha, E. S. P. B.; Pizzolante, C C.; Takahashi, S. E.; Garcia, R. G.; Moreira, J.; Paz, I. C. L. A.; Quinteiro, R. R.; Komiyama, C. M. 2004. Probiotic and prebiotic utilization in diets for free-range broiler chickens. Brazilian Journal of Poultry Science, 6 (2): 99-104.
Rostagno, H. S; Lbino, L. F. T.; Donzele, J. L.; Gomes, P. C.; Oliveira, R. F.; Lopes, D. C.; Ferreira, A. S.; Barreto, S. L. T. 2005. Tabelas brasileiras para aves e suínos: Composição de alimentos e exigências nutricionais. $2^{\mathrm{a}}$ ed. UFV, Departamento de Zootecnia, Viçosa, Brasil, 186pp.

Sader, H. S. 2004. O uso de antimicrobianos promotores de crescimento contribui para a resistência a antibióticos? Anais Fundação Apinco de Ciência e Tecnologia Avícolas, Campinas, Brasil, p.211-217.

Santos, J. R. G; Turnes, C. G. 2005. Probióticos em avicultura. Ciência Rural, 35 (3): 741-747.

Takahashi, S. E.; Mendes, A. A.; Saldanha, E. S. P. B; Pizzolante, C. C.; Pelícia, K.; Quinteiro, R. R.; Komiyama, C. M.; Garcia, R. G.; Almeida, P. I. C. L. 2005. Efficiency of prebiotics and probiotics on the performance, yield, meat quality and presence of Salmonella spp. in carcassses of free-range broiler chickens. Revista Brasileira de Ciência Avícola, 7 (3): 151-157. 